ELECTRONIC LETTER

\title{
Familial renal cell cancer appears to have a recessive component
}

\author{
K Hemminki, X Li
}

J Med Genet 2004;41:e58 (http://www.jmedgenet.com/cgi/content/full/41/5/e58). doi: 10.1136/jmg.2003.014464

$\mathrm{R}$ enal cell cancer (RCC) accounts for $80-90 \%$ of all cancers of the kidney. ${ }^{1}$ Clear cell carcinoma is the most common cell type among parenchymal adenocarcinomas. ${ }^{23}$ Over $2 \%$ of Swedish RCC patients have a parent with RCC, and the familial risk has been about $1.6 .{ }^{4}$ RCC is a manifestation in von Hippel Lindau (VHL) syndrome, in which up to one half of the mutation carriers of the VHL gene are thought to be affected; central nervous system hemangioblastomas and ocular angiomas are other common manifestations in VHL disease. $^{6-9}$ VHL related tumours are of clear cell type, as are tumours in rare familial clusters with or without chromosome 3 translocations and other syndromes with manifested RCC, such as tuberous sclerosis, Birt-Hogg-Dube syndrome, and hereditary non-polyposis colorectal cancer (HNPCC). ${ }^{210}{ }^{11}$ Common to these known syndromes is an apparently dominant mode of inheritance. However, in the population-based studies on familial aggregation, some evidence has been presented that the risk for RCC among siblings could be higher than that between offspring and parents, which could indicate some contribution by a recessive mode of inheritance. ${ }^{12}{ }^{13}$ Intriguingly, to our knowledge, the Swedish data, together with recent Icelandic data, are the only population-based RCC studies where sibling risks have been assessed, and both point to higher familial risks among siblings than among parents and offspring. ${ }^{14}$

The most recent update (from the year 2002) of the Swedish Family-Cancer Database was used to examine specifically the issue of possible recessive inheritance in RCC. This database includes data from Swedish families, totalling over 10.2 million individuals, and cancers from the Swedish Cancer Registry up to the year 2000 and was created by linking registers maintained at Statistics Sweden and the Swedish Cancer Registry; it therefore has unique aspects for family studies because of its national coverage of the population and of medically diagnosed cancers, both derived from registered sources, unaffected by reporting bias.

\section{METHODS}

Statistics Sweden maintains a "Multigeneration Register" where children (offspring) born in Sweden in 1932 and later are registered with their parents (those pleading parenthood at birth) and are organised as families. ${ }^{15}$ Information on the database is also available at the Nature Genetics website as "Supplementary information" to Hemminki and Granström. ${ }^{16}$ The data on families and cancers have complete coverage, except for some groups of deceased offspring who were born in the 1930s and died before 1991; these missing links to parents have a negligible effect on the present results. ${ }^{17}$ This register was linked by individually unique national registration numbers to the Cancer Registry from the years 1958-2000. Cancer registration is considered to be close to $100 \%$ currently. ${ }^{18} \mathrm{~A}$ four-digit diagnostic code according to ICD-7 was used; code 180.0 was used for renal parenchymal tumour and a histology classification was used

\section{Key points}

- Cancer in parents and offspring may be due to dominant causes, whereas cancer affecting only siblings may indicate recessive causes.

- The nationwide Swedish Family-Cancer Database was used to calculate age-standardised relative risks and 95\% confidence intervals for offspring with RCC whose parents or siblings were diagnosed with the same cancer.

- A total of 60 offspring were identified with a first primary RCC whose parents were affected by a concordant cancer and 26 siblings were affected with parents not affected.

- The results from this analysis suggest that, in addition to known dominant inheritance, recessive effects may be important for familial aggregation of RCC.

for adenocarcinoma; the histology code for adenocarcinoma (histology code 96) excludes papillary tumours (code 116). These codes have been used since the start of cancer registration in Sweden (WHO/HS/CANC/24.1 Histology Code). From 1993 onwards, ICD-O-2/ICD with histopathological data according to the Systematized Nomenclature of Medicine (SNOMED, http://snomed.org) was used; this classification is referred to as "SNOMED".

Relative risks (RRs) were used to measure cancer risks for offspring according to the occurrence of cancers in their families; RRs were calculated for offspring whose parent or sibling had RCC, that is using parents or sibling as probands, but only for families of two or more children and with both parents known; no half-siblings were included. Follow-up was started for each offspring at birth, immigration, or l January 1961, whichever came last. Follow-up was terminated on diagnosis of first cancer, death, emigration, or the closing date of the study, which was 31 December 2000. Parents' ages were not limited, but offspring were 0-68 years of age. All tumour incidence rates were based on the data in the Family-Cancer Database, and they are essentially similar to rates in the Swedish Cancer Registry. Adjusted RR was evaluated by means of Poisson regression. ${ }^{19} 20$ This method transforms the underlying incidence rate to a regression function that describes the relationship between predictor variables, gender, family history, age ( 5 year bands) and period ( 10 year intervals), that were estimated directly by maximum likelihood techniques. RRs were calculated

Abbreviations: RCC, renal cell carcinoma; VHL, von Hippel Lindau syndrome 
Age-specific relative risk for RCC in offspring when parents or siblings were probands

\begin{tabular}{|c|c|c|c|c|c|c|c|c|}
\hline \multirow{2}{*}{$\begin{array}{l}\text { Age at } \\
\text { diagnosis } \\
\text { (years) }\end{array}$} & \multicolumn{3}{|c|}{ By parental proband } & \multicolumn{3}{|c|}{ By sibling proband } & \multirow{2}{*}{$\begin{array}{l}\text { RR ratio } \\
\text { (sibling/parent) }\end{array}$} & \multirow[b]{2}{*}{$95 \% \mathrm{Cl}$} \\
\hline & 0 & RR & $95 \% \mathrm{Cl}$ & 0 & RR & $95 \% \mathrm{Cl}$ & & \\
\hline$<50$ & 23 & 3.52 & $2.32-5.34$ & 10 & 18.91 & $10.10-35.39$ & 5.37 & $2.55-11.28$ \\
\hline$\geqslant 50$ & 37 & 2.09 & $1.50-2.89$ & 16 & 7.69 & $4.69-12.58$ & 3.69 & $2.05-6.63$ \\
\hline All & 60 & 2.51 & $1.94-3.24$ & 26 & 10.23 & $6.95-15.07$ & 4.08 & $2.57-6.46$ \\
\hline
\end{tabular}

$\mathrm{O}$, observed; $\mathrm{RR}$, relative risk; $\mathrm{Cl}$, confidence interval.

from exponentiated regression coefficients in the SAS Genmod procedure.

\section{RESULTS}

We identified 60 offspring, aged 0-68 years, with a first primary RCC, whose parents were affected by a concordant cancer (table); the RR was 2.51 (95\% confidence intervals (CIs) 1.94 to 3.24). The RR was higher (3.54) in those diagnosed before age 50 than in those diagnosed at an older age (2.09). None of these offspring had an affected sibling. A total of 26 siblings were affected, giving an RR of 10.23 (6.95 to 15.07) (table). The RR was very high (18.91) among those diagnosed before age 50. The ratio between the RRs, depending on proband status, is also shown in the table. The ratio was 4.08 overall, but it was higher (5.37) among those diagnosed before age 50 years.

In the database, the parental generation is not limited in age but the offspring generation is younger than 69 years. Truncating the parental age also to less than 69 years increased the RR for offspring to $3.84(36,2.76-5.35)$, but the 95\% CIs did not overlap with those for sibling RR, given above. Among the 26 affected siblings, five were diagnosed with a second tumour, including rectal, pancreatic and prostate adenocarcinomas in individual families; however, in one family, both affected siblings presented with brain hemangioblastoma, 4 and 5 years after the diagnosis of RCC. Among affected offspring-parent pairs, no second brain hemangioblastoma were diagnosed in the two generations. The SNOMED histology, available from the years 1993-2000, was not very helpful because most tumours were assigned as "adenocarcinoma" or "nephroblastoma". "Clear cell carcinoma" was indicated only for two siblings from different families.

\section{DISCUSSION}

Familial clustering of cancer may be due to environmental factors shared by family members or due to shared genes. ${ }^{142122}$ We have tried to estimate the contribution of environmental sharing to the familial risk by assessing spouse correlations for cancer, including RCC; no correlation was found for RCC. ${ }^{22}{ }^{23}$ The caveat is that childhood shared effects would be not detected by comparing risks among spouses. However, in analysis of all types of family relationships, a low degree of environmental sharing was noted for RCC. Thus we believe that the present results address mainly heritable effects.

The large difference between risk in families where parents and offspring were affected with RCC (RR 2.51, 95\% CIs 1.94 to 3.24) compared to those where only siblings were affected (RR 10.23, 95\% CIs 6.95 to 15.07) suggests that a recessive mode of inheritance may explain the findings. Accordingly, only one sibling pair of a total of 13 could be ascribed to VHL disease because brain hemangioblastoma was detected as a second neoplasm in both siblings. No other pathognomonic second tumours in the RCC patients or first tumours in their family members pointed to a known syndrome involving RCC. We excluded papillary tumours from the analysis by including only adenocarcinomas, using histology codes, which were available on all cases; unfortunately, the refined SNOMED histology codes were available only since 1993. However, the number of cases was limited and we had no information from distant family members or on any cytogenetic examination of the patients. On the other hand, the data that were available, covering complete families of the Swedish population during the 1900s, were unbiased and all cancer diagnoses were medically verified.

The finding suggestive of a recessive inheritance is somewhat puzzling because none of the known syndromes featuring RCC appear to indicate recessive effects. ${ }^{210} 11$ However, considering that the familial aggregation of RCC is rare and the overall prevalence of RCC is reasonably high, with a cumulative incidence of some $2 \%,{ }^{24}$ the likelihood of detecting a recessive pattern clinically would not be high. Any evidence for consanguinity would strongly support a recessive pattern. The present data suggest that the strategy for finding the putative recessive gene(s) should be mapping for homozygosity for alleles in affected individuals.

\section{Authors' affiliations}

K Hemminki, Division of Molecular Genetic Epidemiology, German Cancer Research Center (DKFZ), Im Nevenheimer Feld 580, 69120 Heidelberg, Germany

K Hemminki, X Li, Biosciences at Novum, Karolinska Institute, 14157 Huddinge, Sweden

Conflicts of interest: none declared.

Correspondence to: K Hemminki, Division of Molecular Genetic Epidemiology, German Cancer Research Center (DKFZ), Im Neuenheimer Feld 580, 69120 Heidelberg, Germany;

k.hemminki@dkfz.de

Received 12 September 2003

Accepted for publication 14 October 2003

\section{REFERENCES}

1 Kumar V, Cotran R, Robbins S. Basic pathology. Philadelphia: WB Saunders, 1997

2 Takahashi M, Kahnoski R, Gross D, Nicol D, Teh BT. Familial adult renal neoplasia. J Med Genet 2002;39:1-5.

3 Bodmer D, van den Hurk W, van Groningen JJ, Eleveld MJ, Martens GJ, Weterman MA, van Kessel AG. Understanding familial and non-familial renal cell cancer. Hum Mol Genet 2002;1 1:2489-98.

4 Czene K, Hemminki K. Kidney cancer from the nation-wide Swedish FamilyCancer Database: familial risks and association with second primary malignancies. Kidney Int 2002;61:1806-13.

5 Hemminki K, Czene K. Attributable risks of familial cancer from the FamilyCancer Database. Cancer Epidemiol Biomarkers Prev 2002;11:1638-44.

6 Maddock I, Moran A, Maher E, Teare M, Norman A, Payne S, Whitehouse R, Dodd C, Lavin M, Hartley N, Super M, Evan D. A genetic register for von Hippel-Lindau disease. J Med Genet 1996;33:120-7.

7 Maher E, Kaelin W. Von Hippel-Lindau disease. Medicine 1997;76:381-32.

8 Friedrich C. Von Hippel-Lindau syndrome. A pleomorphic condition. Cancer 1999:86:2478-82.

9 Hemminki K, Li X, Collins V. A population-based study of familial central nervous system hemangioblastomas. Neuroepidemiology 2001;20:257-61.

10 Iliopoulos O, Eng C. Genetic and clinical aspects of familial renal neoplasms. Semin Oncol 2000;27:138-49.

11 Woodward ER, Clifford SC, Astuti D, Affara NA, Maher ER. Familial clear cell renal cell carcinoma (FCRC): clinical features and mutation analysis of the VHL, MET and CUL2 candidate genes. J Med Genet 2000:37:348-53.

12 Hemminki K, Vaittinen $P$, Dong C, Easton D. Sibling risks in cancer: clues to recessive or X-linked genes? Br J Cancer 2001;84:388-91. 
13 Dong C, Hemminki K. Modification of cancer risks in offspring by sibling and parental cancers from 2,112,616 nuclear families. Int $J$ Cancer

2001;91:144-50.

14 Gudbjartsson T, Jonasdottir TJ, Thoroddsen A, Einarsson GV, Jonsdottir GM, Kristiansson K, Hardarson S, Magnusson K, Gulcher J, Stefansson K, Amundadottir $L$. A population-based familial aggregation analysis indicates genetic contribution in a majority of renal cell carcinomas. Int $J$ Cancer 2002;100:476-9.

15 Hemminki K, Li X, Plna K, Granström C, Vaittinen P. The nation-wide Swedish Family-Cancer Database: updated structure and familial rates. Acta Oncol 2001;40:772-7.

16 Hemminki K, Granström C. Risk for familial breast cancer increases with age. Nat Genet 2002;32:233.

17 Hemminki K, Li X. Familial risk of cancer by site and histopathology. Int J Cancer 2003;103:105-9.
18 Centre for Epidemiology. Cancer incidence in Sweden 2000. Stockholm: The National Board of Health and Welfare, 2002.

19 Clayton D, Schifflers E. Models for temporal variation in cancer rates. I: Ageperiod and age-cohort models. Stat Med 1987;6:449-67.

20 Clayton D, Schifflers E. Models for temporal variation in cancer rates. II: Ageperiod-cohort models. Stat Med 1987;6:469-81.

21 Lichtenstein P, Holm N, Verkasalo P, Illiado A, Kaprio J, Koskenvuo M, Pukkala E, Skytthe A, Hemminki K. Environmental and heritable factors in the causation of cancer. N Engl J Med 2000;343:78-85.

22 Hemminki K, Dong C, Vaittinen P. Cancer risks to spouses and offspring in the Family-Cancer Database. Genet Epidemiol 2001;20:247-57.

23 Hemminki K, Jiang Y. Cancer risks among long-standing spouses. Br J Cancer 2002;86:1737-40

24 IARC, ed. Cancer incidence in five continents. Vol VII. Lyon: IARC, 1997. 